\title{
Productive global health research from Africa: it takes more
}

\author{
Peter Waiswa
}

Received: 3 August 2015/Accepted: 4 August 2015/Published online: 22 August 2015

(C) Swiss School of Public Health 2015

The Swiss Tropical and Public Health Institute (Swiss $\mathrm{TPH}$ ) in Basel hosts this years' European Congress on Tropical Medicine and International Health under the title "Driving the best science to meet global health challenges". With its long-standing African roots, Swiss TPH will certainly bring also many Africans to this conference. This offers an opportunity to reflect about Africans in the global health arena.

It is hard to be an African committed to global health. Every report comparing the world's geographies in health morbidity and mortality (and other areas such as poverty) will end up with similar statements: "and this is highest in Sub-Saharan Africa". This notion has led to many "development agendas" to "help Africa" get out of extreme poverty and disease. More recent has been the soon to end Millennium Development Goals (MDGs) and now the coming so-called "Sustainable Development Goals" (SDGs). Common to most of these initiatives is the conclusion at the end: "progress has been made, but not

This Editorial is part of the special issue "Driving the Best Science to Meet Global Health Challenges" edited on the occasion of the 9th European Congress on Tropical Medicine and International Health 2015.

P. Waiswa $(\bowtie)$

Department of Health Policy, Planning and Management, Makerere University School of Public Health, Uganda, P.O Box 7072, Kampala, Uganda

e-mail: pwaiswa@musph.ac.ug

P. Waiswa

Division of Global Health, Karolinska Institutet, Solna, Sweden

P. Waiswa

Maternal and Newborn Health Research, INDEPTH Network, Accra, Ghana enough especially in Sub-Saharan Africa". They often lack the word "sustainable progress".

I have over time been reflecting on these issues as I travel the world to attend global health meetings every now and then. I ask the question: "Can development be achieved without Africans themselves?" Currently, as we end the MDGs and start on the SDG era, there is a lot of debate, strategizing and maneuvering on "What needs to be done to achieve the SDGs?" These debates are frequently initiated and conducted in the West, often in Washington, New York, London or Geneva. In Africa, once in a while, they might be conducted in Cape Town or Johannesburg, because these are the "more developed worlds", far away from where the actual disease burden is. A few of us Africans from the high burden countries are often invited to either represent our countries or give context. It is true that our countries are poor, but we are just a few specialized, committed, and well-educated individuals. Because we are few and so burdened, our productivity is quite limited. There are huge challenges in developing and exploiting the capacity of educated Africans.

The SDG targets are vague and also very ambitious. To achieve these targets will require that these countries invest not only in health systems but also in their scientists so that adequate capacity is developed. Countries will need people who can internalize evidence, policies, program performance, and design interventions that are equitably accessible, affordable, and have quality. This is a role that cannot be delegated to visiting foreign "experts" as this is neither sustainable nor effective.

How does one facilitate effective capacity building in developing countries in a globalized world? How does an African academic maneuver to be relevant in this everchanging global health world? At the highest academic level, capacity building has taken various forms especially 
in $\mathrm{PhD}$ training. These $\mathrm{PhD}$ trainings have been on the increase, but have they been effective in raising the innovative capacity of countries to deal with the burden they face? The answer is, in my opinion, not much. There are several barriers including trainings being individualized (funding is to an individual), lack of research groups, absence of postdoctoral training and funding, failure to invest in infrastructure (laboratories, libraries and internet), and limited effective mobility of graduates that limits circulation of knowledge and exchange, among others. Added to this is a lack of national funding for research; instead people depend on foreign funding whose agenda and mechanisms are rarely responsive to national priorities. The result is that the scientists rarely focus on any area, or they never actually become specialized.

There are of course exceptions to the rule. In Uganda, among all funders, the Swedish International Development Agency (SIDA) funding stood out in facilitating a more than ten-year joint $\mathrm{PhD}$ training in Makerere University and Karolinska Institutet, Sweden. This has resulted in more than $45 \mathrm{PhD}$ graduates in Uganda and over 500 peerreviewed articles, most led by Ugandans (Sewankambo et al. 2015). This SIDA support for doctoral and postdoctoral program has also built academic infrastructure such as laboratories, libraries, and internet capacity. Another example is the Swiss TPH where training and mutual learning for change is part of mission and strategy. Its long-standing $\mathrm{PhD}$ programs built substantial capacity in Africa. Among the $>240 \mathrm{PhD}$ students who graduated in the first 15 years of this century at Swiss TPH, more than 80 came from abroad and 55 from Africa. Many of these work now in relevant academic positions in Africa (Swiss TPH 2013-2014).

However, from a broader perspective, major gaps remain. In the absence of national funding for research, it is impossible to develop postdoctoral research tracks and sustainable research groups. I call upon African countries to wake up and realize the value of investing in research and development.

Finally, another major challenge is achieving mobility and effective communication for top scientists. This is paramount in global health. Some consider mobility to be "brain circulation" where people share and also bring home new ideas. Effective communication is also hindered by lack of access to fast and reliable internet, and electricity. On the other hand, mobility is not only hindered by the lack of funding but also by the West which tends to "close boarders" even to scientists. Getting a visa is often a ritual with many requirements and long waiting times. A traveling scientist often spends many potentially productive hours chasing for travel documents. It is also not uncommon that visa applications of African scientists get rejected, made too short and/or single entry, or even for one to be embarrassed at ports of entry into foreign lands; this even when duly invited. It will be interesting to know how many African researchers dedicated to be at the Basel conference will fail with visa applications given the more restrictive regulations Swiss authorities had to adopt after an anti-immigration act got accepted in February 2014 by a tiny majority $(50.3 \%)$ of Swiss voters (Wikipedia 2014).

If foreign countries are serious about development and partnership in the post-MDG era, then they need to open up their countries a little more for African scientists. On the other hand, African governments must learn to fund their researchers. It is a shared responsibility.

\section{References}

Swiss TPH Biennial Report (2013-2014). Accessed at http://www. swisstph.ch/resources/publications/biennial-reports/br2013-14. html, and personal communication from Nino Künzli, Deputy Director Swiss TPH (10.6.2015)

Sewankambo N, Tumwine JK, Tomson G, Obua C, Bwanga F, Waiswa P, Katabira E, Akuffo H, Persson K, Peterson S (2015) Enabling dynamic partnerships through joint degrees between low- and high-income countries for capacity development in global health research: experience from the Karolinska Institutet/ Makerere University partnership. PLoS Med 12(2):e1001784. doi:10.1371/journal.pmed.1001784 (eCollection 2015 Feb)

Wikipedia (2014). http://en.wikipedia.org/wiki/Swiss_immigration_ referendum,_February_2014. Accessed 6 Jun 2015 